Revista Brasileira de Agricultura Irrigada v.12, nº.5, p. 2890 - 2896, 2018

ISSN 1982-7679 (On-line)

Fortaleza, CE, INOVAGRI - http://www.inovagri.org.br

DOI: $10.7127 /$ rbai.v12n500856

Protocolo 856.18 - 27/12/2017 Aprovado em 14/09/2018

\title{
GERMINAÇÃO DE Raphanus sativus SUBMETIDA A DIFERENTES CONCENTRAÇÕES DE NaCl
}

Gleidiane Nascimento de Almeida ${ }^{1}$, Gleiciana Nascimento de Almeida ${ }^{1}$, Jenickson Rayron da Silva Costa ${ }^{1}$, Lunara Grazielly Costa da Silva ${ }^{1}$, Elaine Cristina Alves da Silva ${ }^{2}$

\section{RESUMO}

O objetivo deste trabalho foi avaliar a germinação de sementes de rabanete (Raphanus sativus) submetidas à diferentes concentrações de $\mathrm{NaCl}$. O experimento foi conduzido em condições de laboratório na Universidade Federal Rural do Semi-Árido, campus Mossoró- RN. O delineamento experimental utilizado foi inteiramente casualizado com cinco tratamentos salinos $(0 ; 25 ; 50 ; 75$ e $100 \mathrm{mM}$ de $\mathrm{NaCl})$ e quatro repetições de 25 sementes. Foi avaliada a porcentagem de germinação (\%G), a primeira contagem (PC) o índice de velocidade de germinação (IVG), o tempo médio de germinação (TMG) e ao final do experimento, medido o comprimento da parte aérea (CPA) e raiz (CR), bem como determinado o peso seco destes órgãos (PSPA e PSR). Foi observado que a apenas a \%G e a PC não foram afetadas pela salinidade e para as demais variáveis, a concentração de $50 \mathrm{mM}$ de $\mathrm{NaCl}$. O IVG e o CR foram reduzidos a partir da concentração de $50 \mathrm{mM}$ de $\mathrm{NaCl}$ e até esta concentração os valores obtidos na PSPA e PSR foram semelhantes estatisticamente às plantas isentas de sais. O rabanete é tolerante à salinidade até a concentração de $50 \mathrm{mM}$ de $\mathrm{NaCl}$.

Palavras-chave: Salinidade, tolerância, rabanete.

\section{GERMINATION OF Raphanus sativus SUBMITTED TO DIFFERENT CONCENTRATIONS OF NaCl}

\begin{abstract}
The objective of this work was to evaluate the germination of radish (Raphanus sativus) seeds submitted to different concentrations of $\mathrm{NaCl}$. The experiment was conducted under laboratory conditions at the University Federal Rural Semi-Arid, Mossoró-RN. The

\footnotetext{
${ }^{1}$ Graduandos do Curso de Engenharia Florestal, Departamento de Ciências Agronômicas e Florestais, Universidade Federal Rural do Semi-Árido, Mossoró/ RN, Brasil, e-mails: gleidianealmeida1@gmail.com, gleiciana.nascimento@outlook.com, jenickson1@gmail.com, lunaragrazielly@msn.com

2 Profa. Dra, Departamento de Ciências Agronômicas e Florestais, Universidade Federal Rural do Semi-

Árido, Mossoró/ RN, Brasil, e-mail: elainemanancial@gmail.com
} 
experimental design was completely randomized with five saline treatments $(0,25,50$, 75 and $100 \mathrm{mM} \mathrm{NaCl}$ ) and four replicates of 25 seeds. The percentage of germination (\% $\mathrm{G})$, the first count (CF) the germination speed index (ISG), the mean germination time (TGM) and the end of the experiment, measured the length of the aerial part (PAL) and root (RL), as well as the dry weight of the aerial part (PAWD) and of the root (RWD). Was observed that only the\% G and CF was not affected by the salinity and for the other variables, the concentration of $50 \mathrm{mM} \mathrm{NaCl}$. The ISG and RL were reduced from the 50 $\mathrm{mM} \mathrm{NaCl}$ concentration and to this concentration the values obtained in the PAWD and RWD were statistically similar to the salt-free plants. The radish shows tolerance to salinity up to the concentration of $50 \mathrm{mM} \mathrm{NaCl}$.

Keywords: Salinity, tolerance, radish.

\section{INTRODUÇÃO}

O rabanete (Raphanus sativus.) é uma Brassicaceae de porte reduzido, possui raízes globulares de coloração escarlate-brilhante e polpa branca. Adapta-se melhor ao cultivo no outono - inverno, tolerando bem o frio e geadas leves. O desenvolvimento da raiz tuberosa é favorecido por temperaturas baixas e dias curtos, condições que mantêm a planta no estágio vegetativo por mais tempo. É uma oleracea de ciclo curto, intolerante ao transplantio, sendo semeado, portanto, no canteiro definitivo e sua colheita se inicia dos 25-35 dias, após a semeadura direta (FILGUEIRA, 2007).

Segundo Oliveira et al. (2010), o rabanete é uma cultura produzida principalmente por pequenos e médios agricultores, localizados nos cinturões verdes das grandes cidades. Geralmente, é irrigado com água oriunda de fontes superficiais, sendo utilizado, em alguns casos, água de qualidade inferior, principalmente, com elevado teores de sais dissolvidos.

Os problemas decorrentes do acúmulo de sais solúveis e sódio trocável nos solos irrigados das regiões áridas e semi-áridas são muito antigos e sua origem remonta à própria origem da irrigação. A maior parte dos solos salinos e sódicos ocorre nessas áreas onde os processos de salinização e sodificação são frequentemente acelerados por irrigação pouco eficiente e insuficiente drenagem (CORDEIRO, 2013).

$O$ estudo da tolerância de plantas à salinidade é de especial importância, pois o sal é um fator limitante para a produção agrícola, causando dois tipos distintos de estresse, estresse osmótico e estresse iônico por fitotoxicidade específica, o que consequentemente diminui a absorção de nutrientes, provocando distúrbios nas atividades metabólicas em geral afetando o crescimento (HARTER et al., 2014).

A germinação é influenciada pela salinidade dos solos pois os sais interferem no potencial hídrico do solo e reduzem o gradiente de potencial entre o solo e a superfície da semente, o que restringe a captação de água pelas sementes e prejudica as demais fases do processo (LIMA et al., 2005; LOPES et al., 2008). A capacidade de germinar em substrato salino é determinada pelas múltiplas vias bioquímicas que promovem a absorção de água, permitindo que ocorra a germinação (LOPES et al., 2014).

Diante do exposto, este trabalho teve como objetivo avaliar a germinação de sementes e o desenvolvimento inicial de rabanete em diferentes concentrações salinas.

\section{MATERIAL E MÉTODOS}

O trabalho foi realizado no Laboratório de Silvicultura do Centro de Ciências Agrárias, pertencente à Universidade Federal Rural do Semi-Árido (UFERSA), campus Mossoró-RN, no mês de julho de 2017.

O delineamento experimental utilizado foi o inteiramente casualizado, com cinco concentrações salinas (0; 25; 50; 75 e 100 mM de $\mathrm{NaCl}$ ) e quatro repetições de vinte e cinco sementes por tratamento. Para o preparo das soluções salinas, foi adicionado cloreto de sódio $(\mathrm{NaCl})$ a água destilada nos seguintes pesos: 0,0; 
1,46; 2,92; 4,38 e 5,84 g. $\mathrm{L}^{-1}$, correspondendo aos respectivos tratamentos avaliados.

As sementes foram postas para germinar em folha de papel germitest, umedecidas 2,5x o peso do papel, com as soluções descritas anteriormente. Em seguida, os rolos de papel foram acondicionados em sacos plásticos transparentes e mantidos em B.O.D. na temperatura de $25^{\circ} \mathrm{C}$.

As avaliações foram realizadas até o décimo dia após a semeadura, determinando-se a porcentagem de germinação de sementes (\%G), considerando como germinada a emissão de 2 $\mathrm{mm}$ de radícula. No terceiro dia após a implantação do experimento foi avaliada a primeira contagem (PC), computando-se as plântulas normais (BRASIL, 2009). Com os dados da germinação foi calculado o índice de velocidade de germinação (IVG), de acordo com Maguire (1962) e o tempo médio de germinação (TMG), de acordo com Labouriau (1983).
No final do experimento, foram selecionadas dez plântulas por repetição, as quais tiveram a sua parte aérea e raiz principal medidas com auxílio de uma régua. Estas mesmas plântulas foram seccionadas em parte aérea e raiz, acondicionadas em sacos de papel e levadas para a estufa a uma temperatura $65^{\circ} \mathrm{C}$, durante sete dias.

Os dados foram submetidos à análise de variância e as médias comparadas pelo teste de Tukey a 5\% de probabilidade, utilizando o programa estatístico Assistat.

\section{RESULTADOS E DISCUSSÃO}

De acordo com a análise de variância, a salinidade afetou todas as variáveis avaliadas, exceto a porcentagem de germinação e primeira contagem, como pode ser observado na Tabela 1.

Tabela 1. Resumo da análise de variância das variáveis porcentagem de germinação (\%G), primeira contagem (PC), índice de velocidade de germinação (IVG), tempo médio de germinação (TMG), comprimento da parte aérea (CPA), comprimento da raiz (CR), peso seco da parte aérea (PSPA) e peso seco da raiz (PSR) de rabanete (Raphanus sativus) submetidas à diferentes concentrações salinas.

\begin{tabular}{llllllccc}
\hline FV & $\% G$ & PC & IVG & TMG & CPA & CR & PSPA & PSR \\
\hline QM & 34,0 & 184,8 & 34,38 & 0,93 & 4,69 & 21,41 & 100,8 & 10,39 \\
F & $0,63^{\text {n.s }}$ & $2,52^{\text {n.s }}$ & $16,20^{* *}$ & $6,95^{* *}$ & $16,08^{* *}$ & $25,01^{* *}$ & $8,86^{* *}$ & $1,81^{* *}$ \\
\hline CV $(\%)$ & 9,41 & 11,60 & 9,79 & 20,41 & 8,12 & 10,25 & 5,53 & 18,41
\end{tabular}

CV- Coeficiente de variação. ** significativo a $1 \%$ pelo teste $\mathrm{F}$; * significativo a $5 \%$ pelo teste $\mathrm{F}$; ${ }^{\text {(n) }}$ não significativo pelo teste $\mathrm{F}$.

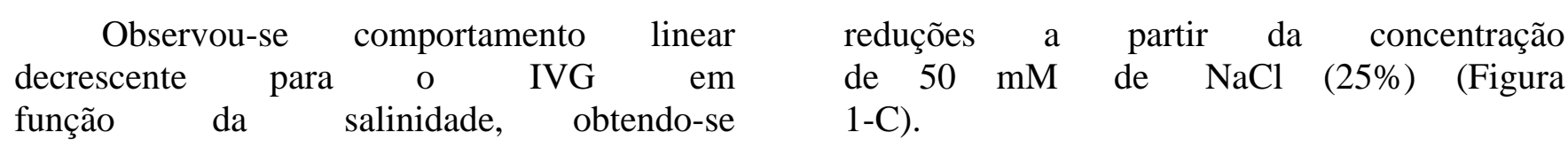


A

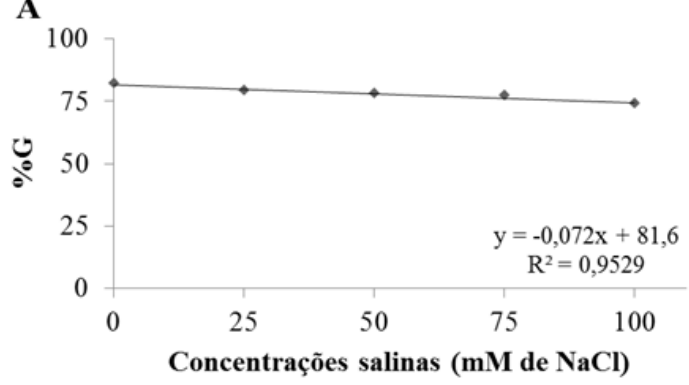

C

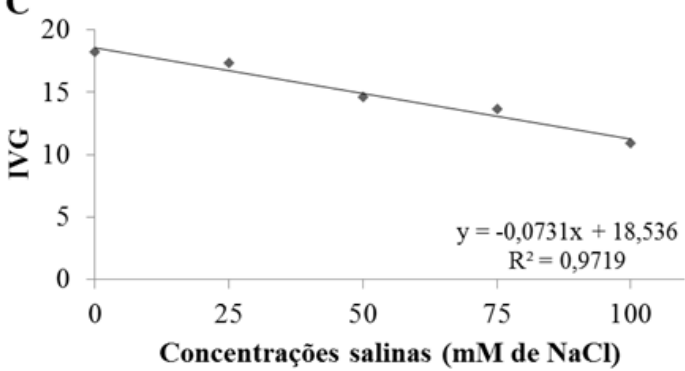

B

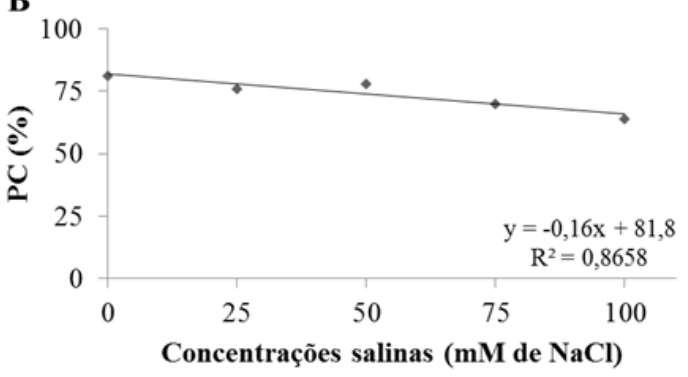

D

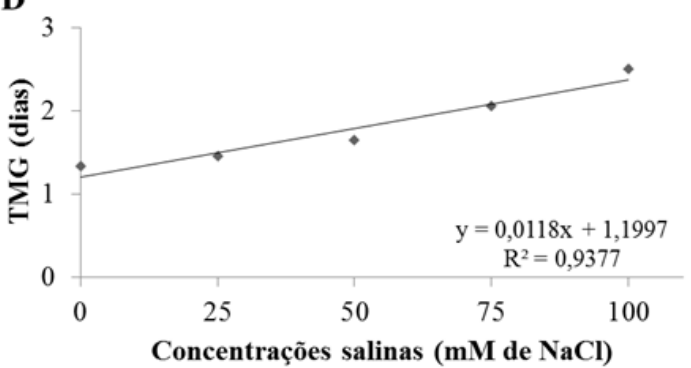

Figura 1. Porcentagem de germinação (\%G), primeira contagem (PC), índice de velocidade de germinação (IVG) e tempo médio de germinação (TMG) de sementes de rabanete (Raphanus sativus), submetidas à diferentes concentrações salinas.

Brunes et al. (2013) observaram que o aumento da concentração salina provocou uma diminuição na taxa de germinação e no IVG em diferentes variedades de aveia branca, a partir da concentração de $75 \mathrm{mM}$ de $\mathrm{NaCl}$. Assim como Ferreira et al. (2007) e Soares et al. (2010), que ao estudarem diferentes híbridos de meloeiro sob salinidade, constataram uma redução na velocidade de emergência das plântulas à medida que os níveis salinos aumentaram.

O TMG apresentou uma regressão linear crescente, onde se pode observar que com o aumento da salinidade, foi necessário um maior tempo para que as sementes submetidas ao nível mais elevado (100 mM de $\mathrm{NaCl}$ ) germinassem (2 dias), enquanto as demais germinaram em torno de 1 dia (Figura 1-D).

$\mathrm{Na}$ cultivar de girassol, Rabbani et al. (2013) e Lewandoski et al., (2016) também constataram um aumento no TMG à medida em que os níveis de sais foram elevados, onde o maior tempo de germinação observado, foi para a concentração de $250 \mathrm{Mol} . \mathrm{m}^{-3}$ (5 dias) e o menor para a testemunha (3 dias). Albuquerque et al.
(2016) também observaram um aumento no TMG de sementes de pepino submetidas a salinidade.

A salinidade afeta o potencial osmótico do substrato, tornando a água indisponível para ser absorvida, no entanto, de acordo com os resultados, as sementes de rabanete se mostraram tolerantes a salinidade, uma vez que a germinação não foi afetada. A redução na disponibilidade hídrica afeta de forma similar todas as espécies, no entanto, nem todas as culturas são afetadas pelo mesmo nível de salinidade, e algumas culturas ao ser mais tolerantes que outras, consegue extrair a água com mais facilidade e germinar de forma satisfatória (AYERS; WESTCOT, 1991).

Para o comprimento da parte aérea, as plântulas que germinaram na concentração de 25 e $50 \mathrm{mM}$ de $\mathrm{NaCl}$, apresentaram um aumento de 31 e 19\%, respectivamente, em relação as que foram isentas de sais. Já para o comprimento da raiz, a salinidade afetou a partir da concentração de $50 \mathrm{mM}$ de $\mathrm{NaCl}$, reduzindo $28 \%$, em relação ao controle (Tabela 2).

Tabela 2. Média dos valores do comprimento da parte aérea (CPA), comprimento da raiz (CR), peso seco da parte aérea (PSPA) e peso seco da raiz (PSR) de plântulas de rabanete submetidas a diferentes concentrações salinas. 


\begin{tabular}{|c|c|c|c|c|}
\hline $\begin{array}{l}\text { Tratamentos } \\
\text { (mM de } \mathrm{NaCl} \text { ) }\end{array}$ & $\begin{array}{l}\text { CPA } \\
\text { (cm) }\end{array}$ & $\begin{array}{c}\mathrm{CR} \\
\text { (cm) }\end{array}$ & $\begin{array}{c}\text { PSPA } \\
\text { (mg) }\end{array}$ & $\begin{array}{l}\text { PSR } \\
\text { (mg) }\end{array}$ \\
\hline 0 & $6,11 c$ & $11,25 a$ & $55,22 b$ & $14,25 a$ \\
\hline 25 & $8,0 \mathrm{a}$ & $11,50 \mathrm{a}$ & $57,52 b$ & $14,40 a$ \\
\hline 50 & $7,3 \mathrm{cb}$ & $8,05 b c$ & $60,27 b$ & $13,77 a$ \\
\hline 75 & $6,3 \mathrm{bc}$ & $8,23 b$ & $67,25 a$ & $11,67 b$ \\
\hline 100 & $5,3 c$ & $6,08 \mathrm{c}$ & $64,97 a$ & $10,87 b$ \\
\hline
\end{tabular}

Foi observado que o peso seco da parte aérea das plântulas correspondentes aos tratamentos de 75 e $100 \mathrm{mM}$ de $\mathrm{NaCl}$ apresentaram um aumento de 21 e 17\%, em relação ao tratamento controle. Já nas raízes foi observado o inverso, onde estas plântulas apresentaram uma redução de, aproximadamente, $18 \%$. Resultados semelhantes foi constatado por Hater et al. (2014) que ao estudarem 0 efeito da salinidade em mogango observaram que a partir da concentração de $25 \mathrm{mM}$ de $\mathrm{NaCl}$ houve um aumento de $24 \%$ para a fitomassa da parte aérea e uma redução na raiz.

Diversas culturas tais como o girassol (SOUSA et al., 2012), aveia branca (TIMM et al., 2015) e coentro (SALES et al., 2015) tem seu peso seco reduzido em função da salinidade. Os resultados obtidos para o peso seco pode ser atribuído ao fato das plântulas que foram submetidas aos níveis mais elevados de sais terem deslocado suas reservas da raiz para a parte aérea.

Embora a cultura do rabanete seja classificada como moderadamente sensível à salinidade, com o limiar de 1,2 dS. $\mathrm{m}^{-1}$, de acordo com Ayers e Westcot (1991), na presente pesquisa ela apresentou-se como tolerante até 50 $\mathrm{mM}$ de $\mathrm{NaCl}$.

\section{CONCLUSÃO}

Embora a salinidade não afete a porcentagem de germinação e a primeira contagem, o índice de velocidade de germinação e o comprimento da parte aérea são reduzidos a partir da concentração de $50 \mathrm{mM}$ de $\mathrm{NaCl}$, e até esta concentração, o peso seco da parte aérea e da raiz não são afetados.
$\mathrm{O}$ rabanete é tolerante à salinidade até a concentração de $50 \mathrm{mM}$ de $\mathrm{NaCl}$.

\section{REFERÊNCIAS}

AYERS, R. S.; WESTCOT, D. W. A qualidade da água na agricultura. Campina Grande: UFPB, 1991. 218 p.

ANDRÉO-SOUZA, Y.; PEREIRA, A. L.; SILVA, F. F. S.; RIEBEIRO-REIS, R. C.; EVANGELISTA, M. R. V.; CASTRO, R. D.; DANTAS, B. F. Efeito da salinidade na germinação de sementes e no crescimento inicial de mudas de pinhão-manso. Revista Brasileira de Sementes, v.32, n.2, p. 83-92, 2010. DOI: http://dx.doi.org/10.1590/S0101-

31222010000200010

ALBUQUERQUE, J. R. T.; SÁ, F. V. S.; OLIVEIRA, F. A.; PAIVA, E.P.; ERBIA BRESSIA GONÇALVES ARAÚJO, E. B. G.; SOUTO, L. S. Crescimento inicial e tolerância de cultivares de pepino sob estresse salino. Revista Brasileira de Agricultura Irrigada, v. 10, n. 2, p. $486 \quad$ - 495, 2016. DOI: http://dx.doi.org/10.7127/rbai.v10n200355

BRASIL. Ministério da agricultura. Regras para análise de sementes. Brasília: DNDV/CLAV, 2009. 394 p.

BRUNES, A. P.; FONSECA, D. A. R.; RUFINO, C. A.; TAVARES, L. C.; TUNES, L. M.; VILLELA F. A. Crescimento de plântulas de aveia branca submetidas ao estresse salino. Semina: Ciências Agrárias, v. 34, n. 6, suplemento 1, p. 3455-3462, 2013. DOI: http://dx.doi.org/10.5433/1679-

0359.2013v34n6Supl1p3455 
CORDEIRO, G, G. Salinidade em áreas irrigadas. Petrolina, 2003. Disponível em:<http://www.cpatsa.embrapa.br/artigos/ salinidade. html.> Acesso em: 27 Set.2017.

FERREIRA, G. S.; TORRES, S. B.; COSTA, A. R. F. C. Germinação e desenvolvimento inicial de plântulas de meloeiro em diferentes níveis de salinidade da água de irrigação. Revista Caatinga, v. 20, n. 3, p. 181-185, 2007.

FERRO, M.G. F.; COSTA, R.H.; JÚNIOR, J.P.F.A.; BARBOSA, A.L.P.; SANTOS, M.A.L. Análise da cultura do rabanete submetida a diferentes níveis de salinidade e lâminas de irrigação. In: III INOVAGRI INTERNATIONAL MEETING, 3, 2016, Fortaleza. Anais...Fortaleza: INOVAGRI, 2015.

FILGUEIRA, F. A. R. Novo Manual de Olericultura: Agrotecnologia moderna na produção e comercialização de hortaliças. 3 . ed. Viçosa: UFV, 2007. 421 p.

HARTER, L. S. H.; F. S. HARTER; DEUNER, F. S. C. MENEGHELLO, G. E. VILLELA, F. A. Salinidade e desempenho fisiológico de sementes e plântulas de mogango. Horticultura Brasileira, v. 32, p. 80-85, 2014. DOI: http://dx.doi.org/10.1590/S0102-

05362014000100013

JAMIL, M.; REHMAN, S. U.; LEE, K. J.; KIM, J. M.; KIM, H. S.; RHA, E. S. Salinity reduced growth PS2 photochemistry and chlorophyll content in radish. Scientia Agricola, v.64, n.2, p.111-118, 2007.2 DOI: http://dx.doi.org/10.1590/S010390162007000200002

LEWANDOSKI, C. F.; LEITE, D.; LENZ, N. B. G.; BUENO, P. L.; GRALICK, J.; SANTOS, R. F.; SILVEIRA, L.; BRESSAN, R. T. Avaliação da germinação de girassol em estresse salino. Acta Iguazu, v.5, n.3, p. 47-57, 2016.

LIMA, M. G. S.; LOPES, N. F.; MORAES, D. M.; ABREU, C. M. Qualidade fisiológica de sementes de arroz submetidas a estresse salino. Revista Brasileira de Sementes, v.27, n.1, p.54-
61, 2005. DOI: http://dx.doi.org/10.1590/S010131222005000100007

LOPES, J. C.; MACEDO, C. M. P. Germinação de sementes de couve chinesa sob influência do teor de substrato e estresse salino. Revista Brasileira de Sementes, v.30, n.3, p.7985, 2008. DOI: http://dx.doi.org/10.1590/S010131222008000300011

LOPES, K. P.; NASCIMENTO, M. G. R.; BARBOSA, R. C. A.; COSTA, C. C. Salinidade na qualidade fisiológica em sementes de Brassicas oleracea L. var. itálica. Semina: Ciências Agrárias, Londrina, v. 35, n. 5, p. 2251-2260, 2014.2 DOI: http://dx.doi.org/10.1590/S010205362014000100013

OLIVEIRA, F. R. A.; OLIVEIRA, F. A.; MEDEIROS, J. F.; SOUSA, V. F. L.; FREIRE, A. G. Interação entre salinidade e fósforo na cultura do rabanete. Revista Ciência Agronômica, v.41, n.4, p.519-526, 2010. DOI: http://dx.doi.org/10.1590/S180666902010000400003

SALES, M. A. L.; MOREIRA, F. J. C.; ELOI, W. M.; RIBEIRO, A. A.; SALES, F. A. L.; MONTEIRO, R. N. F. GERMINAÇÃO E CRESCIMENTO INICIAL DO COENTRO EM SUBSTRATO IRRIGADO COM ÁGUA SALINA. Brazilian Journal of Biosystems Engineering, v. 9, n. 3, p. 221-227, 2015. DOI: http://dx.doi.org/10.18011/bioeng2015v9n3p22 $1-227$

SANTOS, M. R.; BRITO, C. F. B. Irrigação com água salina, opção agrícola consciente. Revista Agrotecnologia, v.7, n.1, p.33-41, 2016. DOI: http://dx.doi.org/10.12971/5175

SOARES, A. N. R.; RIBEIRO, M. C. C.; BENEDITO, C. P.; OLIVEIRA, F. N.; GUIMARÃES, L. M. S. Crescimento inicial de plântulas de acesso de melão (Cucumis melo L.) crioulo submetido ao estresse salino. Revista Verde de Agroecologia e Desenvolvimento Sustentável, v. 5, n. 3, p. 224230, 2010. 
SOUSA, J. R. M.; SOARES, L. A. A.; SOUSA JUNIOR, J. R.; MAIA P. M. E.; SILVA, S. S.; MARACAJÁ, P. B. Germinação de sementes de girassol cv. brs 324 submetidas a estresse salino simulado por $\mathrm{NaCl}$. Agropecuária Científica no SemiÁrido, v.8, n.3, p. 123-127, 2012. DOI: http://dx.doi.org/10.30969/acsa.v8i3.46 6
TIMM, F. C.; $\quad$ BANDEIRA, J. M.; BICCA, M. L.; DODE, J. S.; MORAES, D. M. Germinação e crescimento de plântulas de genótipos de aveia branca submetidas ao estresse salino. Semina: Ciências Agrárias, $\quad$ v. 36, n. 5, $\quad$ p. 29873000, $015 . \quad$ DOI: $10.5433 / 1679-$ 0359.2015v36n5p2987 